\title{
PMKT2, a new killer toxin from Pichia membranifaciens, and its promising biotechnological properties for control of the spoilage yeast Brettanomyces bruxellensis
}

\author{
Correspondence \\ D. Marquina \\ dommarq@bio.ucm.es
}

Received 25 August 2008

Revised 4 November 2008

Accepted 5 November 2008

\author{
A. Santos, M. San Mauro, E. Bravo and D. Marquina
} Department of Microbiology, Biology Faculty, Complutense University of Madrid, 28040 Madrid,
Spain

\section{INTRODUCTION}

Worldwide, microbial growth destroys large amounts of various products, causing yield losses in the agronomical and biotechnological industries. Traditionally, biocides have been used to deal with these problems but different disadvantages such as establishment of resistant strains and suppression of natural competitors have made alternatives such as biological control necessary (Beever et al., 1989; Raposo et al., 2000). Biological control strategies include natural plant- and animal-derived compounds, as well as antagonistic micro-organisms (Ciani \& Fatichenti, 2001).

During recent decades, microbiological control of spoilage micro-organisms has evolved as a possibility. Many yeast strains and other micro-organisms inhibiting plant pathogens have been reported, especially within the fruit- and vegetable-producing sector, and several new products have reached the commercial market (Janisiewicz \& Korsten, 2002). The suggested modes of action of biocontrol yeasts are not likely to constitute any hazard for the consumer (Janisiewicz et al., 2001; Masih \& Paul, 2002; Comitini et al., 2004; Santos \& Marquina, 2004a).

The food and beverage industries were among the first to explore the application of killer-toxin-producing yeasts to kill spoilage micro-organisms (Lowes et al., 2000). Yeast strains often achieve competitive advantage by producing killer toxins, which kill off competing sensitive cells belonging to either the same or a different species (Young, 1987; Ciani \& Fatichenti, 2001). The most thoroughly studied examples are the Saccharomyces cerevisiae toxins $\mathrm{K} 1, \mathrm{~K} 2$ and $\mathrm{K} 28$; producers of these toxins are able to kill each other, but are immune to killer toxins of their own class. The genetically very well-characterized killer toxin $\mathrm{K} 1$ is stable within a narrow range of acidic $\mathrm{pH}$, is unstable at temperatures above $25^{\circ} \mathrm{C}$, and can be inactivated by agitation. It is a heterodimeric $\alpha / \beta$ protein encoded by an M1 virus with a double-stranded RNA genome (Wickner, 1986; Martinac et al., 1990; Bostian et al., 1984; Breinig et al., 2002).

Killer toxins are not restricted to Saccharomyces; they can also be found in other yeast genera: Candida, Cryptococcus, Debaryomyces, Hanseniaspora, Hansenula, Kluyveromyces, Pichia, Sporidiobolus, Tilletiopsis, Zygosaccharomyces, etc. Studies of a variety of killer toxins have shown that the characteristics of the K1 killer toxin and other toxins tend to be similar (most of them are protease-sensitive heatlabile proteins that are stable and active only at acidic $\mathrm{pH}$ values), while the genetic bases of killer characters are quite 
variable. There is also diversity in the mode of action of killer toxins. Several killer toxins (K1, PMKT) seem to be poreforming-related toxins (Breinig et al., 2002; Santos \& Marquina, 2004b). K28, from S. cerevisiae, has been found to cause sensitive yeasts to arrest proliferation as unbudded cells, suggesting that it blocks completion of the cell cycle (Schmitt et al., 1996), whereas zymocin, from Kluyveromyces lactis, exerts a tRNase activity (Butler et al., 1991; Studte et al., 2008). Finally, HM-1, from Hansenula mrakii, kills sensitive cells, presumably by interfering with $\beta$ - $(1 \rightarrow 3)$ glucan synthesis (Takasuka et al., 1995).

The genus Pichia, which comprises 91 species, is currently one of the largest yeast genera. Yeasts of this genus are widely distributed and can be found in natural habitats such as soil, water, plant exudates, insects and fruits and also as contaminants in a variety of foods and beverages and high-sugar-containing products (Heard \& Fleet, 1987; Noronha-da-Costa et al., 1996). Some species of this genus have beneficial effects in food; for example, they contribute to the early stages of wine fermentation and in the processing of different types of cheeses (Lenoir, 1984; Heard \& Fleet, 1988, 1990; Lambrechts \& Pretorius, 2000; Fernandez et al., 2000). Strains of Pichia membranifaciens are common contaminants in food-related environments and occur with high frequency in fermenting olive brines (Marquina et al., 1992, 1997). Within the genus Pichia, which is heterogeneous from a taxonomic point of view (Kurtzman \& Fell, 1998; Kurtzman \& Robnett, 1998), P. acaciae (McCracken et al., 1994; Klassen et al., 2008), P. anomala (Comitini et al., 2004; Wang, et al., 2007; Izgü et al., 2007), P. farinosa (Suzuki \& Nikkuni, 1994), P. inositovora (Klassen \& Meinhardt, 2003) and P. kluyveri (Middelbeek et al., 1979) produce different killer toxins. Killer toxins from the genus Pichia have heterogeneous mechanisms of activity; some of them have similar characteristics to that determined for the P. membranifaciens PMKT (Santos \& Marquina, 2004a; Pfeiffer \& Radler, 1984; Middelbeek et al., 1979), and others do not. PaT, the killer toxin produced by $P$. acaciae, has a tRNase activity (Klassen et al., 2008) whereas P. anomala NCYC 434 has an exo- $\beta$-1,3-glucanase activity against sensitive yeast strains (Izgü et al., 2007).

Recently, it has been shown that $P$. membranifaciens produces a killer toxin (PMKT) that is active on spoilage yeasts and fungi (Santos et al., 2000, 2004). PMKT has extensive activity against different micro-organisms but only under restricted conditions, and therefore is of interest for its potential application as an antimicrobial agent, but only in permissive environments (Llorente et al., 1997; Santos \& Marquina, 2004a).

Previous biochemical studies indicated that PMKT is an $18 \mathrm{kDa}$ protein that interacts with the cell wall, first with the $(1 \rightarrow 6)-\beta$-D-glucans (Santos et al., 2000) and then with CWP2p, a GPI-anchored protein (Santos et al., 2007). Regardless of certain possible additional effects, PMKT acts by disrupting plasma membrane electrochemical gradients, leading to the death of sensitive cells (Santos \& Marquina, 2004b). Exploring the global gene expression responses of S. cerevisiae to PMKT, several core environmental stressresponse genes were induced, corroborating the idea that the coordinated transcriptional response to PMKT is related to changes in ionic homeostasis. The HOG (high osmolarity glycerol) signalling pathway is activated in response to PMKT (Santos et al., 2005).

The broad spectrum of killer activity of PMKT against yeasts and fungi is very promising, although it seems to be necessary to obtain new killer toxins with both increased killer activities against sensitive strains and higher stabilities against physico-chemical conditions of the environment for wider biotechnological applications. New killer toxins can be used to eliminate undesirable contaminating yeasts during fermentations by conferring the killer character on starter strains and can be considered as biocontrol agents in the preservation of foods (Petering et al., 1991). The killer character can also be a useful means of biotyping pathogenic yeasts, and killer toxins are potential antimicrobial agents in the treatment of infections. In this study, our main purposes were to purify and characterize a new killer toxin from $P$. membranifaciens CYC 1086, to compare the purified killer toxin (named PMKT2) with the most studied killer toxin (PMKT) from P. membranifaciens CYC 1106 and to use the new promising biochemical characteristics of this new killer toxin for the biocontrol of yeasts and filamentous fungi of agronomical interest. PMKT2 exerted killer activity against Brettanomyces bruxellensis, a wine spoilage yeast. In smallscale fermentations using sterilized grape juice, PMKT2 was able to inhibit B. bruxellensis, indicating its potential applicability in a particular biotechnological field.

\section{METHODS}

Strains and general media. Pichia membranifaciens CYC 1086 was the killer toxin producer used in this study (Complutense Yeast Collection, Complutense University of Madrid, Spain), originally isolated from olive brines (Marquina et al., 1992), identified according to conventional methods used in yeast taxonomy and deposited at the Portuguese Yeast Culture Collection (PYCC, Caparica, Portugal). The killer toxin from P. membranifaciens CYC 1086 (named PMKT2) was compared in the present study with PMKT obtained from P. membranifaciens CYC 1106 (Santos \& Marquina, 2004a; Santos et al., 2005, 2007). The sensitive strain used for routine killer assays was Candida boidinii IGC 3430 (PYCC), originally isolated from olive brines. C. boidinii has been linked to pernicious effects (lipolytic activity and lactic acid assimilation) on the fermentation of olive brines. The strains were maintained on agar slants containing $0.5 \%(\mathrm{w} / \mathrm{v})$ yeast extract (Difco), $1 \%$ peptone (Difco), $2 \%$ glucose and $2 \%$ agar at $20{ }^{\circ} \mathrm{C}$. Yeast isolates were obtained from Tempranillo grapes and grape skins from Spanish vineyards and wine fermentations of the Ribera del Duero region. These strains were gifts from Dr E. Navascues (Agrovin SA), isolated and identified according to conventional methods used in yeast taxonomy (Kurtzman \& Fell, 1998).

For the purpose of killer toxin production and purification, $P$. membranifaciens CYC 1086 was cultured in buffered YMB medium 
[1\% (w/v) glucose, $0.3 \%(\mathrm{w} / \mathrm{v})$ yeast extract (Difco), $0.3 \%(\mathrm{w} / \mathrm{v})$ malt extract (Difco) and $0.5 \%(\mathrm{w} / \mathrm{v})$ proteose peptone no. 3 (Difco)]. The medium was buffered to $\mathrm{pH} 4.5$ with $0.2 \mathrm{M}$ sodium citrate/ phosphate. Killer activity was determined in YMAMB: YMA (YMB with agar) supplemented with $30 \mathrm{mg}$ of methylene blue per litre, $6 \%$ (w/v) $\mathrm{NaCl}$ and $2 \%(\mathrm{w} / \mathrm{v})$ agar (Llorente et al., 1997).

DBDM (Dekkera/Brettanomyces differential medium) plates were used for the distinction and enumeration of B. bruxellensis strains during mixed cultures in must (Rodrigues et al., 2001).

Grape juice was obtained from Tempranillo grapes from Spain ( $\mathrm{pH} 3.5$, sugar $220 \mathrm{~g} \mathrm{l}^{-1}$ ) and sterilized by using $0.22 \mu \mathrm{m}$ Millipore filters. Additionally, grape must agar (GMA) was developed with sterile must and $2 \%(\mathrm{w} / \mathrm{v})$ agar for the determination of killer activity in conditions related to wine fermentation.

Killer toxin assay. We assayed killer toxin with a diffusion test (Woods \& Bevan, 1968), using $6 \mathrm{~mm}$ diameter antibiotic assay AA Whatman paper discs on YMAMB seeded with the sensitive strain. The diameter of the inhibition zone was used as a measure of the yeast killer activity, and killer toxin activity was expressed in arbitrary units (AU) (Barandica et al., 1999). Under the experimental conditions used, a linear relationship was observed between the logarithm of the protein concentration in the solution tested and the diameter of the inhibition zone. One AU is defined as the amount of toxin resulting in an inhibition zone with a $1 \mathrm{~mm}$ diameter. For calculations of the specific activity, protein contents were estimated using the Bradford method, with BSA as standard.

Screening for $\boldsymbol{P}$. membranifaciens killer phenotypes. Several strains identified as $P$. membranifaciens were tested for killer activity against a panel of selected sensitive strains (Table 1). Strains to be tested for killer activity were inoculated in $\sim 1 \mathrm{~cm}$ diameter concentrated zones onto YMAMB plates previously seeded with a lawn $\left(5.0 \times 10^{5}\right.$ cells $\left.\mathrm{ml}^{-1}\right)$ of the yeast tested for sensitivity, which had been grown in YMA medium and suspended in sterile water just before inoculation. The plates were incubated for a week at $20^{\circ} \mathrm{C}$. Killer yeasts were identified by a clear zone of inhibition surrounding them.

Killer spectrum against fungi and yeast strains of agronomical significance. With the aim of determining the feasibility of the biocontrol of several micro-organisms linked with agronomical problems, we assayed the killer activity of $P$. membranifaciens CYC 1086 and CYC 1106 against a panel (Table 2) of yeasts and fungi. Killer activity was determined as above.
Production of killer toxin. Killer yeast was cultivated for 3 days at $20{ }^{\circ} \mathrm{C}, 150$ r.p.m. in 21 Erlenmeyer flasks with 11 YMB. After centrifugation $\left(5000 \mathrm{~g}, 10 \mathrm{~min}, 4{ }^{\circ} \mathrm{C}\right)$ the supernatant was adjusted to a final glycerol concentration of $15 \%(\mathrm{v} / \mathrm{v})$ and concentrated to a volume of $100 \mathrm{ml}$ by tangential ultrafiltration with a $10 \mathrm{kDa}$ cut-off membrane [Minisette membrane cassette, omega type (Filtron Technology)]. Ice-cold ethanol was added to a final concentration of $45 \%(\mathrm{v} / \mathrm{v})$ and, following $30 \mathrm{~min}$ incubation at $0-4{ }^{\circ} \mathrm{C}$, the resulting precipitate was separated by centrifugation $(8000 \mathrm{~g}, 10 \mathrm{~min}$, $\left.0{ }^{\circ} \mathrm{C}\right)$. The proteins in the supernatant were precipitated by further addition of ice-cold ethanol up to a final concentration of $75 \%(\mathrm{v} / \mathrm{v})$. The resulting pellet was dissolved in $5 \mathrm{ml} 1 \mathrm{mM}$ sodium citrate/ phosphate buffer $(\mathrm{pH} 4.0)$ and the solution was used as killer toxin concentrate for subsequent characterization.

Effect of proteolytic enzymes. The effects of the proteolytic enzymes Pronase, pepsin and papain (Sigma) on the killer activity of P. membranifaciens CYC 1086 were examined as described by Santos \& Marquina (2004a).

Temperature and pH stability of PMKT2. For stability to $\mathrm{pH}$, concentrated toxin samples were adjusted with $0.1 \mathrm{M}$ sodium citrate/ phosphate buffer at a range of $\mathrm{pH}$ values between 3 and 10. The solutions were incubated at $20{ }^{\circ} \mathrm{C}$ for $1 \mathrm{~h}$ and killer activity was determined with $C$. boidinii as sensitive yeast. With the aim of determining the stability in grape must against B. bruxellensis 1D007, lyophilized killer extracts were resuspended in grape must previously adjusted to $\mathrm{pH}$ values between 3 and 10 .

Samples of killer toxin were incubated at a range of different temperatures: $5,10,15,20,25,30$ and $32{ }^{\circ} \mathrm{C}$. Aliquots $(30 \mu \mathrm{l})$ were removed at specific intervals and killer activity was assayed. The same was done to determine the temperature stability in grape must against B. bruxellensis 1D007. Lyophilized killer extracts were resuspended in grape must and incubated at temperatures between 5 and $32{ }^{\circ} \mathrm{C}$, as described above.

Influence of temperature and pH on PMKT2 activity. To determine activity at different $\mathrm{pH}$ values, activity plates or GMA plates adjusted to $\mathrm{pH}$ values between 2.5 and 10 were seeded with the sensitive strains (C. boidinii and B. bruxellensis 1D007, respectively) and incubated at $20{ }^{\circ} \mathrm{C}$ in the presence of aliquots of the killer toxin $(30 \mu \mathrm{l})$. The inhibition zone was determined after 3 days incubation.

To determine the activity at different temperatures, YMAMB and GMA plates were incubated at $4{ }^{\circ} \mathrm{C}$ for $24 \mathrm{~h}$ with the killer toxin $(30 \mu \mathrm{l})$ from concentrated culture supernatants to ensure the

Table 1. Screening for new $P$. membranifaciens killer phenotypes

\begin{tabular}{|c|c|c|c|c|c|c|c|c|c|c|}
\hline \multirow[t]{2}{*}{ Sensitive strain } & \multicolumn{10}{|c|}{ P. membranifaciens killer strains ${ }^{\star}$ (relative activity) $\dagger$} \\
\hline & 1 & 2 & 3 & 4 & 5 & 6 & 7 & 8 & 9 & 10 \\
\hline C. boidinii IGC 3430 & $3+$ & $2+$ & $4+$ & $3+$ & $3+$ & $3+$ & $3+$ & $3+$ & $3+$ & $4+$ \\
\hline K. lactis IGC 4358 & $2+$ & $2+$ & $2+$ & $2+$ & $2+$ & $2+$ & $2+$ & - & - & - \\
\hline P. membranifaciens IGC 4619 & $2+$ & $2+$ & $3+$ & $2+$ & $2+$ & $2+$ & $2+$ & $1+$ & $3+$ & $4+$ \\
\hline Saccharomyces bayanus IGC 4465 & - & - & - & - & $3+$ & $3+$ & - & - & - & - \\
\hline S. cerevisiae IGC 4456 & $2+$ & $2+$ & $2+$ & $2+$ & - & $2+$ & - & - & - & - \\
\hline S. cerevisiae IGC 4620 & - & $2+$ & $2+$ & $2+$ & $2+$ & - & - & - & - & - \\
\hline S. exiguus IGC 4612 & $2+$ & $2+$ & $2+$ & $2+$ & $2+$ & - & - & - & - & - \\
\hline
\end{tabular}

${ }^{\star}$ Killer strains of P. membranifaciens: 1, CYC 1048; 2, CYC 1095; 3, CYC 1106; 4, CYC 1111; 5, CYC 1112; 6, CYC 1108; 7, CYC 1090; 8, CYC 1084; 9, CYC 1085; 10, CYC 1086.

$\dagger+$, Killing activity; -, no killing activity. 
Table 2. Killer activity of $P$. membranifaciens CYC 1086 and CYC 1106 against yeasts and fungi of biotechnological interest

\begin{tabular}{|c|c|c|c|c|c|c|c|c|}
\hline \multirow[t]{2}{*}{ Sensitive strain } & \multicolumn{2}{|c|}{ Killer activity } & \multirow[t]{2}{*}{ Sensitive strain } & \multicolumn{2}{|c|}{ Killer activity } & \multirow[t]{2}{*}{ Sensitive strain } & \multicolumn{2}{|c|}{ Killer activity } \\
\hline & 1086 & 1106 & & 1086 & 1106 & & 1086 & 1106 \\
\hline S. cerevisiae $\mathrm{CEG}$ & - & - & B. bruxellensis D013 & $1+$ & - & Pichia membranifaciens CYC 1070 & $2+$ & - \\
\hline S. cerevisiae VRB & - & $3+$ & B. bruxellensis D014 & $1+$ & - & Aspergillus spp. 27 & - & - \\
\hline S. cerevisiae NEM & - & - & B. bruxellensis D015 & $1+$ & - & A. carbonarius B MUM & - & - \\
\hline S. cerevisiae 2323 & - & - & B. bruxellensis D019 & $1+$ & - & A. tubingensis & - & - \\
\hline S. cerevisiae ALB & - & $3+$ & B. bruxellensis D027 & $1+$ & - & Fusarium culmorum & - & - \\
\hline S. cerevisiae SLO & - & $4+$ & B. bruxellensis D028 & $1+$ & - & F. graminearum NRRL 28525 & - & - \\
\hline S. cerevisiae $\mathrm{VN}$ & - & - & B. bruxellensis D029 & $2+$ & - & F. graminearum NRRL 29020 & - & - \\
\hline S. cerevisiae $71 \mathrm{~B}$ & - & $4+$ & B. bruxellensis D031 & $1+$ & - & F. pone & - & - \\
\hline S. cerevisiae 16 & - & - & B. bruxellensis D038 & $1+$ & - & F. reticulloides MM 7-3 & - & - \\
\hline S. cerevisiae 17 & - & $3+$ & Debaryomyces hansenii 1021 & - & - & F. sporotrichoides ITEM 550 & - & - \\
\hline S. cerevisiae 18 & - & $3+$ & D. hansenii 1244 & - & - & Botrytis cinerea 20003 & - & $3+$ \\
\hline S. cerevisiae 19 & - & - & D. hansenii 10388 & - & - & B. cinerea 20004 & - & $1+$ \\
\hline S. cerevisiae $\mathrm{SC} 1$ & - & $4+$ & D. hansenii 10386 & - & - & B. cinerea 20005 & - & $2+$ \\
\hline
\end{tabular}

complete diffusion. The plates were then seeded with the sensitive strains (C. boidinii and B. bruxellensis 1D007, respectively) and incubated at different temperatures up to $37^{\circ} \mathrm{C}$ (Fig. 2b).

Binding of PMKT2 to cell-wall fractions. The sensitive strain was grown on YMB (without buffer) and cultured $48 \mathrm{~h}$ at $30{ }^{\circ} \mathrm{C}$. Cell walls from C. boidinii IGC 3430 were prepared by mechanical disruption (Fleet, 1991). After being washed, cell walls were lyophilized and stored in a desiccator. Glucans (fractions S-1, S-2, P-1 and P-2) were extracted as described by Manners et al. (1973). Mannoproteins were extracted and partially purified from cell walls by Cetavlon (cetyltrimethylammonium bromide) fractionation (Schmitt \& Radler, 1987; Santos et al., 2000) and chitin was obtained as described by Fleet (Fleet \& Phaff, 1973; Fleet, 1991).

Binding of killer toxin was estimated from the amount of killer toxin remaining in solution after incubation (Santos et al., 2000). Approximately $2000 \mathrm{AU}$ killer factor per $\mathrm{ml}$ was added to a suspension of $20 \mathrm{mg}$ of the cell-wall fractions per ml. Samples were stirred gently and then centrifuged $(10000 \mathrm{~g}, 30 \mathrm{~s})$. The amount of killer activity remaining in solution after incubation was measured by the diffusion test method.

Binding of killer toxin to different polysaccharides. The following polysaccharides were used for toxin binding studies: polysaccharides with $(1 \rightarrow 4)-\alpha$ as the main glucosidic linkage (amylose, amylopectin and polygalacturonic acid); pullulan, a $(1 \rightarrow 4)-\alpha$ - and $(1 \rightarrow 6)-\alpha$-polysaccharide; xylan and chitin, $(1 \rightarrow 4)-\beta$ polysaccharides; laminarin, a $(1 \rightarrow 3)$ - $\beta$-polysaccharide; liquenan, a $(1 \rightarrow 3)-\beta$ - and $(1 \rightarrow 4)$ - $\beta$-polysaccharide; and $(1 \rightarrow 6)-\beta$-polysaccharides (pustulan and a glucan obtained from Penicillium allahabadense). These polysaccharides ( $15 \mathrm{mg}$ each) were added to $1 \mathrm{ml}$ killer toxin $\left(150 \mathrm{AU} \mathrm{ml} \mathrm{m}^{-1}\right)$. Mixtures were shaken gently and then centrifuged $(10000 \mathrm{~g}, 30 \mathrm{~s})$. The amount of killer activity remaining in solution was assayed. Amylose and amylopectin were obtained from SigmaAldrich.
Killer toxin purification. The killer toxin was purified from native PAGE by directly using the killer toxin concentrate obtained as stated above. The toxin concentrate was dissolved in a $0.1 \mathrm{M}$ glycine $/ \mathrm{HCl}$ sample buffer ( $\mathrm{pH} 2.5$ ) with methyl green as tracking dye. Polyacrylamide gels $(8 \%)$ were prepared in a $0.1 \mathrm{M}$ glycine $/ \mathrm{HCl}$ buffer ( $\mathrm{pH}$ 2.5). Samples were electrophoresed for $5 \mathrm{~h}, 200 \mathrm{~V}$, at $4{ }^{\circ} \mathrm{C}$. To determine the activity of the killer toxin, one-third of the gel was cut into slices $(2 \mathrm{~mm})$ and these were transferred to YMAMB plates seeded with the sensitive strain. For the visualization of protein bands, the other two-thirds of the gel were stained with Coomassie brilliant blue R-250 or extracted with distilled water for HPLC purification.

Toxin purification was done on a Varian 920-LC Analytical HPLC system, which included a fraction collector and a UV detector working at $280 \mathrm{~nm}$ at an ambient temperature of $20{ }^{\circ} \mathrm{C}$. The crude protein obtained from the previous native PAGE was dialysed against $10 \mathrm{mM} \mathrm{Na} \mathrm{HPO}_{4} /$ citric acid buffer, $\mathrm{pH}$ 4.5. The protein samples were loaded onto a Hydrocell GPC 1500 column, $7.8 \times 300 \mathrm{~mm}$ (Biochrom Laboratories), which was pre-equilibrated with the sample buffer. Elution was done with the same buffer at a flow rate of $1 \mathrm{ml}$ $\min ^{-1}$. Fractions of $200 \mu \mathrm{l}$ volume were collected and assayed for killer activity. The active fractions from different runs were pooled, concentrated and then subjected to SDS-PAGE. All the chemicals were HPLC grade and obtained from Merck.

Following native PAGE and HPLC, dialysed fractions containing killer toxin activity were subjected to electrophoresis for a total of $1.5 \mathrm{~h}$ at $120 \mathrm{~V}$, according to the method described by Laemmli (1970), under denaturing conditions, using $8 \%$ acrylamide gels in reducing ( $\beta$-mercaptoethanol) and non-reducing conditions.

Determination of the isoelectric point. Isoelectric focusing was performed at $4{ }^{\circ} \mathrm{C}$ in polyacrylamide gels $(12 \mathrm{~cm} \times 6.5 \mathrm{~cm} \times 0.4 \mathrm{~mm})$ containing $0.5 \mathrm{ml}$ ampholytes, $\mathrm{pH}$ range 2.5-5.0 (Pharmalyte, Pharmacia), $2 \mathrm{ml}$ acrylamide/bisacrylamide solution (24.25\%/ 
$0.75 \%), 2 \mathrm{ml}$ glycerol $(20 \%$, v/v), $150 \mathrm{ml}$ ammonium persulphate $(10 \%, \mathrm{w} / \mathrm{v}), 35 \mathrm{ml}$ TEMED and distilled water $(5.5 \mathrm{ml})$. Pre-focusing, sample application and focusing were carried out as published previously (Santos \& Marquina, 2004a).

Activity of PMKT2 in grape juice. In order to verify the potential of PMKT2 as a biological anti- $B$. bruxellensis agent in winemaking, cells of B. bruxellensis strains 1D007, D013 and D017 (with different sensitivity to P. membranifaciens CYC 1086; Table 2) were grown to exponential phase in sterilized must $(0.22 \mu \mathrm{m}$ Millipore filters $)$ for $16 \mathrm{~h}$ at $20{ }^{\circ} \mathrm{C}$, collected and subsequently resuspended in must containing PMKT2 $\left(2000 \mathrm{AU} \mathrm{ml}^{-1}\right)$. The final cell concentration was $2 \times 10^{6}$ cells ml $^{-1}$. A control with heat-inactivated killer toxin was run in parallel (not shown). Incubation was done at $20{ }^{\circ} \mathrm{C}$ with shaking (125 r.p.m.). Aliquots were taken periodically and further 10 -fold serial dilutions were made. Volumes of $50 \mu \mathrm{l}$ were used for plating on YMA medium. Colonies were counted after growth at $30{ }^{\circ} \mathrm{C}$. The killer activity remaining in solution during the experiment was determined by taking $1 \mathrm{ml}$ samples. Samples were centrifuged and the supernatant was lyophilized and resuspended in $0.1 \mathrm{ml} 0.1 \mathrm{M}$ citrate/phosphate buffer $\mathrm{pH}$ 4.5. Finally, the activity was determined as described above.

Mixed cultures. Mixed cultures of S. cerevisiae SC1, B. bruxellensis 1D007 and P. membranifaciens CYC 1086 were done in pairs with inocula ratio of $1: 1$. Cellular concentrations were adjusted to $10^{5}$ cells $\mathrm{ml}^{-1}$ and growth developed in grape juice by incubation at $20{ }^{\circ} \mathrm{C}$ in $125 \mathrm{ml}$ Erlenmeyer flasks with agitation (125 r.p.m.). During the co-fermentation, growth rates were determined and compared with those obtained during the fermentation in axenic cultures. Aliquots were taken periodically and further serial 10-fold dilutions were made. Volumes of $50 \mu \mathrm{l}$ were used for plating on YMA and DBDM media. Colonies were counted after growth at $30{ }^{\circ} \mathrm{C}$. The killer activity remaining in solution during the experiment was determined as above.

\section{RESULTS}

\section{Screening for $\boldsymbol{P}$. membranifaciens killer phenotypes}

In order to determine if the available killer-toxin-producing yeast strains of $P$. membranifaciens belong to different toxin types, several strains were tested against a panel of sensitive yeast strains employing the usual technique with methylene blue agar plates (Woods \& Bevan, 1968). Strains producing the same toxin may have a similar spectrum of killer activity whereas strains producing different toxins may inhibit different strains. Results are presented in Table 1. Different profiles of killer activity were observed. The first profile was represented by strains CYC 1095, 1106 and 1111, which have the same activity against sensitive yeasts, and also strains CYC 1048 and 1112, which were very similar to this profile, although slightly different. The second profile was represented by strains CYC 1084, 1085, 1086 and also probably strain CYC 1090 . On the basis of these results, we selected P. membranifaciens CYC 1086 because of its different killer spectrum activity in comparison to $P$. membranifaciens CYC 1106, the best-studied killer strain of P. membranifaciens (Santos et al., 2000, 2005, 2007; Santos \& Marquina, 2004a). We used this yeast to investigate the potential biotechnological application of this killer activity and its biochemical nature.

\section{Killer activity against fungal and yeast strains of agronomical significance}

Killer activity against a range of yeasts and filamentous fungi was tested with the aim of determining whether the killer toxin of $P$. membranifaciens CYC 1086 has potential for biotechnological application (Table 2). Activity against several yeasts was observed. All the strains of B. bruxellensis were sensitive to $P$. membranifaciens CYC 1086 whereas none of the $S$. cerevisiae strains, isolated from oenological fermentations, showed sensitivity. This was an important result because $B$. bruxellensis is a major problem in the wine industry, where it produces unpleasant odours and tastes during wine ageing, due to the production of 4ethylphenol. Strain CYC 1086 was also effective against $P$. membranifaciens CYC 1070; it is known that P. membranifaciens is a normal inhabitant of the grape berry surface and fermenting must, and it can develop during fermentation excreting undesirable metabolites into the wine.

Filamentous fungi were more resistant to $P$. membranifaciens CYC 1086: only two strains of Fusarium proliferatum (strains MM 1-2 and 3-1) were sensitive. No activity was found against Botrytis cinerea strains whereas P. membranifaciens CYC 1106 was very active, as reported by Santos et al. (2004).

\section{Proteinaceous nature of the killer toxin}

P. membranifaciens CYC 1086 exhibits a pronounced killer activity against a variety of yeast species and fungi (Tables 1 and 2). To determine whether PMKT2 activity on sensitive strains was due to the production of a protein or glycoprotein, similar to all other yeast killer toxins so far characterized, including PMKT, we examined the effects of different proteases on killing ability. Treatment of the concentrated culture supernatant with Pronase or papain led to the loss of $100 \%$ of the initial killer activity. In contrast, pepsin was less effective against PMKT2: a residual activity of about $40 \%$ was found after pepsin treatment.

\section{Temperature and pH stability of the killer toxin}

The killer toxin produced by P. membranifaciens CYC 1086 was stable only within a narrow $\mathrm{pH}$ range (2.5-4.8). No significant differences were observed between the stability at different $\mathrm{pH}$ values in must or standard conditions (Fig. 1). Stability was lost at temperatures above $20{ }^{\circ} \mathrm{C}$ in aqueous buffers and must at the appropriate $\mathrm{pH}$ value (Fig. 2c, d). Stability was quickly lost at $45{ }^{\circ} \mathrm{C}$ and $65{ }^{\circ} \mathrm{C}$ (30 $\mathrm{min}$ and $5 \mathrm{~min}$, respectively) (not shown).

\section{Effect of temperature and pH on killer activity}

The killer protein was active only at acidic $\mathrm{pH}$ values (Fig. 1), with the optimal pH between 3.5 and 4.5. Optimal temperature was $20{ }^{\circ} \mathrm{C}$ (Fig. 2a, b). The results were very similar when standard conditions or must were used. 

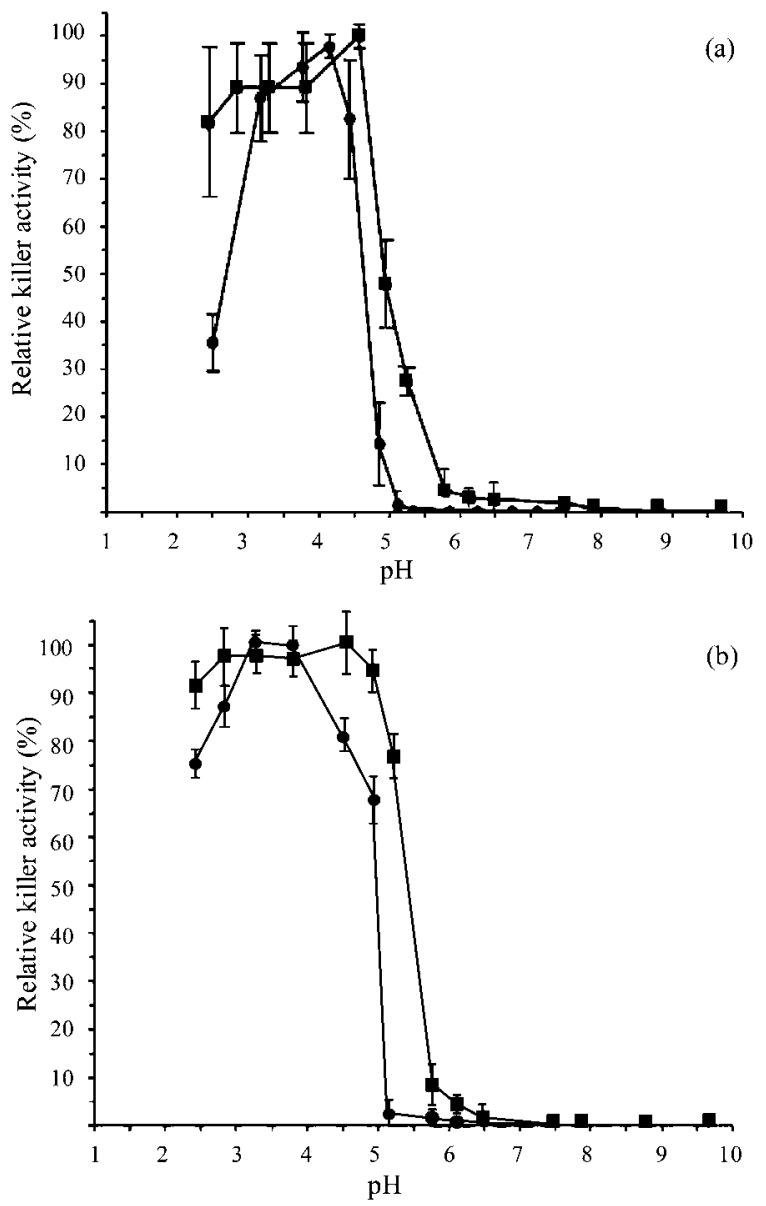

Fig. 1. Activity (O) and stability ( $\square$ ) of the killer toxin from $P$. membranifaciens CYC 1086 at different $\mathrm{pH}$ values in standard conditions (a) and grape must (b). Means \pm SD $(n=3)$.

\section{Binding of PMKT2 to cell-wall fractions and polysaccharides}

None of the polysaccharides tested, composed of $(1 \rightarrow 4)-\beta$-, $(1 \rightarrow 4)-\alpha-,(1 \rightarrow 3)-\beta-,(1 \rightarrow 6)-\beta-,(1 \rightarrow 6)-\alpha$ - or some mixture of these linkages, were able to bind PMKT2, indicating that the binding capacity of the toxin is not related to the polysaccharides tested. A complementary study was done by determining the binding capacity of different cell-wall fractions of the sensitive strain. Glucan fractions of the cell wall were unable to bind PMKT2, whereas mannoproteins and mannan were able to, indicating that PMKT2 has a different receptor in the cell wall of the sensitive strain than PMKT (Table 3).

\section{Killer toxin purification and determination of isoelectric point}

Once the protein nature and characteristics of the toxin produced had been established, the secreted protein was purified from the supernatant of a growing culture of $P$. membranifaciens CYC 1086 at the early stationary phase. The killer toxin that accumulated in the culture fluid increased as growth progressed and then levelled off as the culture reached the stationary phase (not shown). The ultraconcentrated killer toxin was subjected to acidicnative polyacrylamide electrophoresis. Taking into account that the isoelectric point of the toxin, determined in polyacrylamide gels, was estimated as about 3.7, the migration of the toxin in acidic PAGE ( $\mathrm{pH} 2.5)$ was low, although the toxin was electrophoresed for $5 \mathrm{~h}$ (Fig. 3b). The HPLC-purified killer toxin was observed to have a molecular mass of about $30 \mathrm{kDa}$. A low recovery $(16 \%)$ of killer activity was obtained after a 2636-fold purification (Table 4).

\section{Killer activity in winemaking conditions}

Small-scale trials conducted in winemaking conditions determined that PMKT2 is suitable for potential biotechnological applications. PMKT2 inhibited B. bruxellensis strains 1D007, D013 and D017. Death rates were $0.13 \mathrm{~h}^{-1}$, $0.09 \mathrm{~h}^{-1}$ and $0.11 \mathrm{~h}^{-1}$, respectively (Fig. 4). Furthermore, in mixed cultures on grape must, $P$. membranifaciens CYC 1086 was able to compete with strain 1D007, showing that this killer yeast exerts an effective competition against $B$. bruxellensis. The killer activity remaining in solution during cell death was reduced significantly in the first hour. Then killer activity was constant, indicating that there is an excess of toxin remaining in solution and the toxin is able to bind to the sensitive cells during the first moments of the killing action.

In axenic cultures on grape juice, without toxin addition, specific growth rates of $P$. membranifaciens CYC 1086, $S$. cerevisiae $\mathrm{SC} 1$ and $B$. bruxellensis $1 \mathrm{D} 007$ were $0.11,0.13$ and $0.07 \mathrm{~h}^{-1}$, respectively (Fig. 5a). The presence of the killer strain or its purified killer toxin did not change the growth parameters of the fermentative S. cerevisiae strain (Fig. 5c), indicating that these two yeasts are compatible in winemaking conditions, whereas B. bruxellensis 1D007 showed significant inhibition (death rate, $0.12 \mathrm{~h}^{-1}$ ) in mixed cultures (Fig. 5b). Furthermore, no killer activity remaining in solution was detected in mixed cultures during the first $3 \mathrm{~h}$, indicating that the produced toxin was attached to the sensitive cells. Probably, when all the binding sites of the toxin in the sensitive cells were saturated the presence of the toxin would be detected in the medium.

\section{DISCUSSION}

Yeasts and moulds can have both positive and negative effects on products consumed by humans and animals. Yeasts are used as starter cultures in cheeses and bread, as well as wine, beer and other alcoholic fermentation products, but they can also initiate spoilage in foods, such as fruit juice and salads. Indeed, spoilage yeasts have been isolated from many foods and beverages (Suriyarachchi \& Fleet, 1981; Izgu et al., 1997; Jakobsen \& Narvhus, 1995). 

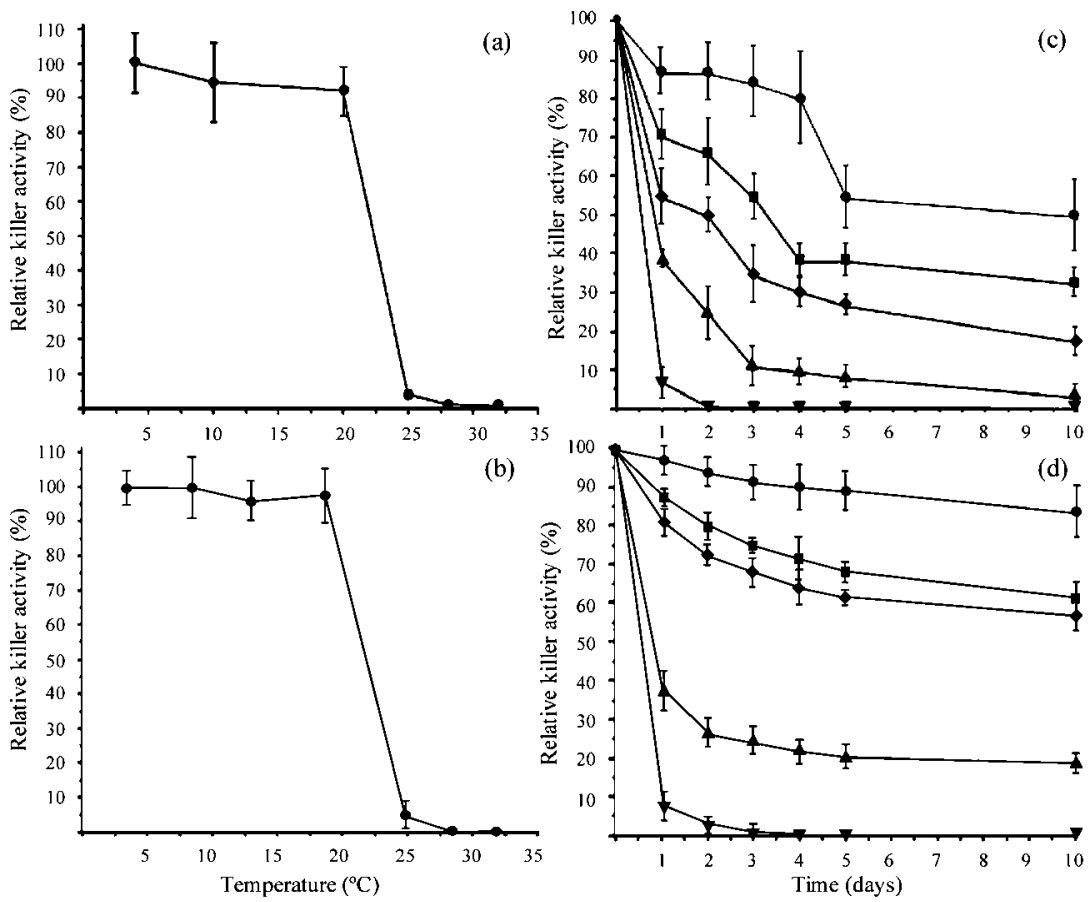

Fig. 2. (a, b) Activity of the killer toxin from $P$. membranifaciens CYC 1086 at different temperatures in standard conditions (a) and grape must (b). (c, d) Stability of killer toxin at different temperatures over a period of 7 days: $20{ }^{\circ} \mathrm{C}(\bullet) ; 25{ }^{\circ} \mathrm{C}(\boldsymbol{\square}) ; 28{ }^{\circ} \mathrm{C}(\boldsymbol{\nabla}) 32{ }^{\circ} \mathrm{C}(\boldsymbol{\Delta})$ and $37{ }^{\circ} \mathrm{C}(\boldsymbol{\nabla})$, in standard conditions (c) and grape must (d). Means \pm SD $(n=3)$.

Mould spoilage destroys large amounts of pre-harvested and harvested fruit, vegetables and cereal grains, and is often associated with mycotoxin formation (Marín et al., 2008).

In recent years, biological control strategies have been considered as a desirable alternative to chemicals. Biological control with yeasts and bacteria has been suggested as one such alternative to the application of fungicides (Petersson \& Schnürer, 1995; Druvefors, et al., 2005; Druvefors \& Schnürer, 2005).

In studies of the potential of mycogenic yeasts as biocontrol agents, workers have focused on the production of mycocins in situ by natural toxin producers or transformed yeasts (Kimura et al., 1995). P. membranifaciens produces a toxin, PMKT, which is very stable at low $\mathrm{pH}$ and temperature values and has a broad spectrum of activity (Llorente et al., 1997). We found that this toxin could be a versatile antispoilage agent in foods with the limitations imposed by its stability. Different approaches are possible when the use of a killer toxin is necessary; inoculation with killer yeast, crude extracts of killer toxins or purified toxins, such as PMKT, could be used as an additive in acidic buffers (Santos \& Marquina, 2004a; Santos et al., 2004).

Table 3. Adsorption of PMKT2 to different polysaccharides and cell-wall fractions

\begin{tabular}{|lccc|}
\hline Polysaccharide & Main linkages & $\begin{array}{c}\text { Residual killer } \\
\text { activity (\%) }\end{array}$ & Adsorption \\
\hline Mannan & $\alpha(1 \rightarrow 6), \alpha(1 \rightarrow 2)$ and $\alpha(1 \rightarrow 3)$ & 10 & + \\
Mannoproteins & $\alpha(1 \rightarrow 6), \alpha(1 \rightarrow 2)$ and $\alpha(1 \rightarrow 3)$ & 10 & - \\
P-1 fraction & $\beta(1 \rightarrow 6)$ & 95 & - \\
P-2 fraction & $\beta(1 \rightarrow 3)$ & 95 & - \\
Amylose & $\alpha(1 \rightarrow 4)$ & 95 & - \\
Amylopectin & $\alpha(1 \rightarrow 4)$ and $\alpha(1 \rightarrow 6)$ & 90 & - \\
Pullulan & $\alpha(1 \rightarrow 6)$ & 95 & - \\
Laminarin & $\beta(1 \rightarrow 3)$ & 90 & - \\
Xylan & $\beta(1 \rightarrow 4)$ & 100 & - \\
Chitin & $\beta(1 \rightarrow 4)$ & 100 & - \\
Pustulan & $\beta(1 \rightarrow 6)$ & 90 & - \\
Glucan from Penicillium allahabadense & $\beta(1 \rightarrow 6)$ & 90 & - \\
Glucan from Penicillium erythromellis & $\beta(1 \rightarrow 6)$ & 95 & \\
\hline
\end{tabular}



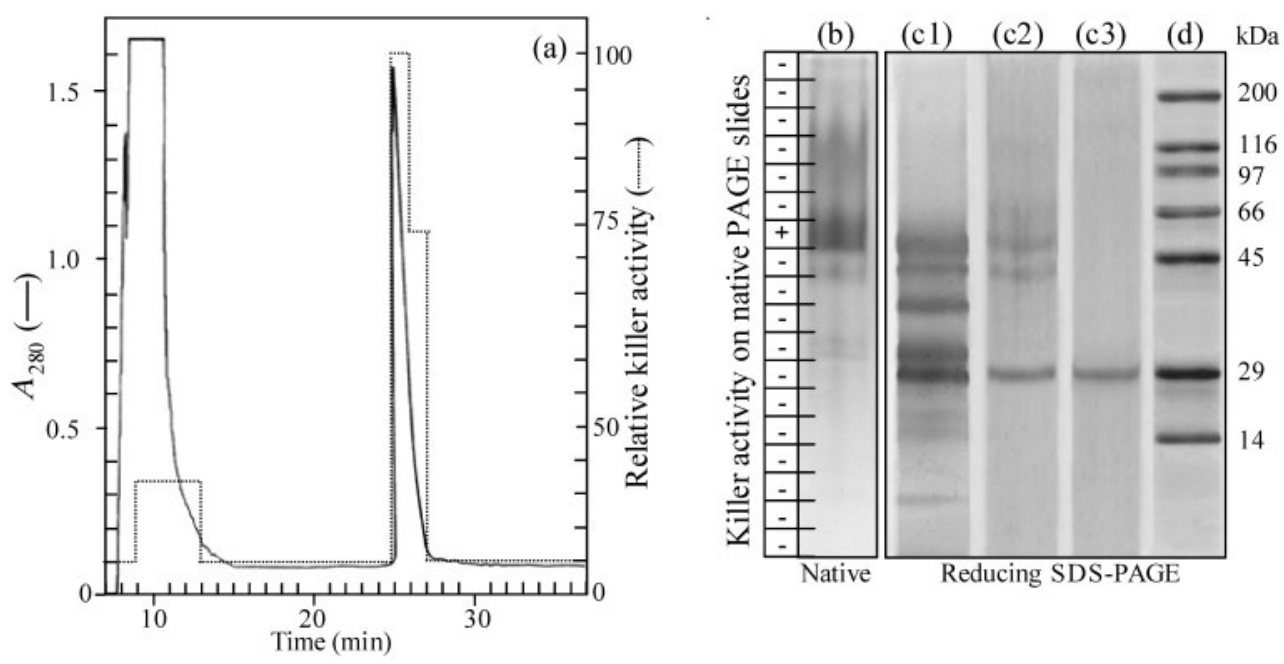

Fig. 3. (a) Elution pattern from a Hydrocell GPC 1500 HPLC column of proteins from active sections of native PAGE. (b) Aliquots from HPLC were recovered and tested for activity and homogeneity in SDS-PAGE. (c1) Coomassie-blue-stained SDS-PAGE gel of a P. membranifaciens CYC 1086 crude extract. (c2) Protein extract of an active section from native PAGE. (c3) HPLC-purified killer toxin. (d) Molecular mass standards.

This paper confirms the observation that different killer toxins are produced by different isolates of the same species. The fact that multiple toxins are produced by $P$. membranifaciens must be noted, although it is similar to the reported killer system of $S$. cerevisiae, which is composed of three different toxins (Schmitt \& Breinig, 2006). The strains of $P$. membranifaciens available in our laboratory produced at least two different types of toxins, named PMKT and PMKT2. PMKT2 had physico-chemical properties and molecular mass similar to PMKT, but their spectra of biological activity against a variety of fungal and yeast strains were different, indicating that they were different toxins (Tables 1 and 2). PMKT2 was active at acidic $\mathrm{pH}$ values and temperatures below $20{ }^{\circ} \mathrm{C}$, although in comparison to PMKT, it was more stable for short periods at higher temperatures and neutral $\mathrm{pH}$ values (not shown), indicating that this new toxin is more suitable than PMKT for biotechnological applications.
Furthermore, PMKT inhibits strains of Saccharomyces but PMKT2 does not, and PMKT was not able to inhibit several B. bruxellensis isolates, whereas PMKT2 did so (Table 2). These differences in killer spectra could be accounted for by the preliminary differences observed between the two toxins in the nature of the primary receptors present in the sensitive strains (Table 3). PMKT was found to have affinity for $(1 \rightarrow 6)-\beta$-D-glucans whereas PMKT2 was found to be adsorbed by cell-wall mannoproteins (Table 3), suggesting the presence of two different primary receptors for these toxins (Breinig et al., 2002; Hutchins \& Bussey, 1983; Takasuka et al., 1995; Takita \& Castilho-Valavicius, 1993).

In the wine industry, B. bruxellensis is considered a spoilage yeast due to its ability to produce volatile phenols conferring off-odours and losses of fruity sensorial qualities in wines (Suárez et al., 2007). B. bruxellensis is a constant

Table 4. Purification of PMKT2 from the supernatant of a buffered-YMB-grown culture

\begin{tabular}{|c|c|c|c|c|c|c|c|}
\hline \multirow[t]{2}{*}{ Fraction } & \multirow[t]{2}{*}{ Volume (ml) } & \multicolumn{2}{|c|}{ Protein } & \multirow[t]{2}{*}{ Activity (AU) } & \multirow{2}{*}{$\begin{array}{c}\text { Sp. act. } \\
\left(\mathrm{AU} \mathrm{mg}^{-1}\right)\end{array}$} & \multirow{2}{*}{$\begin{array}{l}\text { Factor } \\
\text { (-fold) }\end{array}$} & \multirow[t]{2}{*}{ Yield (\%) } \\
\hline & & $\left(\mathrm{mg} \mathrm{ml}^{-1}\right)$ & (mg) & & & & \\
\hline Tangential ultrafiltration & 75 & 11.35 & 851 & 31000 & 36 & 2.2 & 64.6 \\
\hline $75 \%$ ethanol precipitate & 5 & 130.45 & 652 & 29500 & 45 & 2.7 & 61.5 \\
\hline
\end{tabular}

${ }^{*}$ Native PAGE was done by applying $20 \mu$ aliquots per well of the $75 \%$ ethanol precipitate. Calculations were done with the assumption that the complete amount $(5 \mathrm{ml})$ from the ethanol precipitate was applied to the native PAGE. 


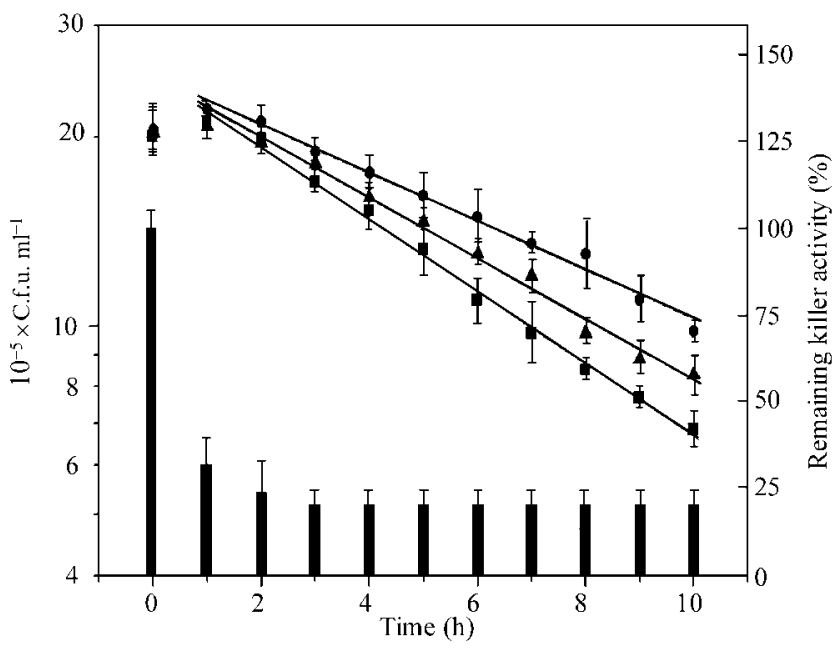

Fig. 4. Time-course of PMKT2 activity in grape must against sensitive $B$. bruxellensis strains. Microbial counts of $B$. bruxellensis $1 \mathrm{D} 007(\boldsymbol{\square}), \mathrm{D} 013(\mathbf{0})$ and D017 ( $\mathbf{A})$ were obtained by plating on YMA after incubation with PMKT2. The killer toxin remaining unbound (bars) was determined and expressed as relative killer activity. Means $\pm \mathrm{SD}(n=3)$.

wine resident but it develops mainly at the end of fermentation, when other microbial species decline. It is a strong resistant species, withstanding nutrient deprivation (Aguilar Uscanga et al., 2000), high ethanol concentrations (Medawar et al., 2003), initial cold maceration, thermal treatment (Couto et al., 2005) and winery disinfection (Renouf \& Lonvaud-Funel, 2004; Renouf et al., 2005, 2006, 2008). Therefore, B. bruxellensis can be considered as one of the best-adapted species to the cellar and wine environment. Tools for limiting its growth are restricted. Thus, the investigation of promising new additives, such as PMKT2, as new treatments to prevent B. bruxellensis growth during and after fermentation is very promising. In the present work, small-scale fermentations in winemaking conditions determined that $P$. membranifaciens CYC 1086 and its killer toxin (PMKT2) are suitable for winemaking applications. PMKT2 showed killer activity against $B$. bruxellensis in similar conditions as those prevailing in wine fermentation, and in addition, $S$. cerevisiae was unaffected, indicating that the killer yeast or PMKT2 are compatible with the fermentative process of winemaking.

In conclusion, we have here described a new killer toxin of P. membranifaciens that is active against Brettanomyces spoilage yeasts. The activity and stability of the toxin are compatible with the $\mathrm{pH}$ and temperature values of wine production, showing that PMKT2 may have potential as a biocontrol agent of undesirable wine spoilage yeasts. The specificity of this toxin is also very compatible with wineproducing strains because no PMKT2-sensitive strains of S. cerevisiae were found.

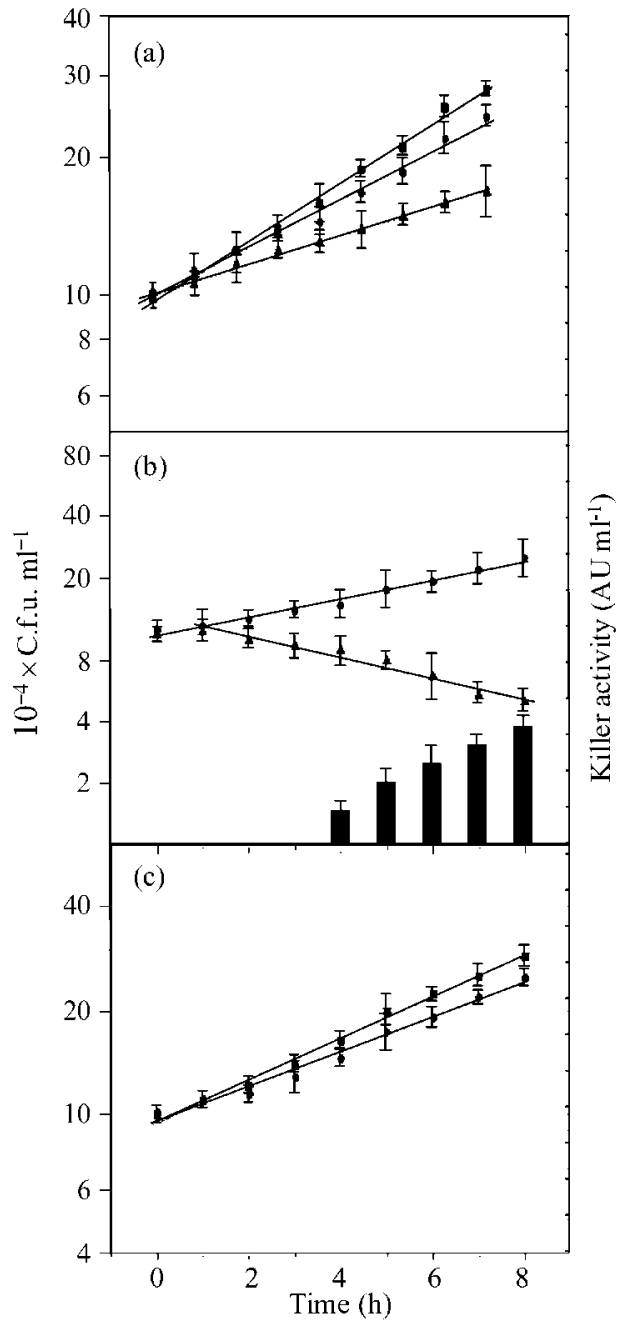

Fig. 5. Determination of the killer effect of $P$. membranifaciens CYC 1086 in mixed cultures growing in grape must. (a) Axenic

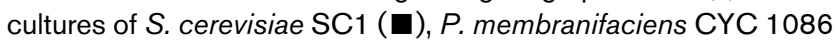
(O) and $B$. bruxellensis 1D007 ( $\mathbf{\Delta}$ ). (b) Mixed cultures of $B$. bruxellensis 1D007 (A) vs P. membranifaciens CYC $1086(\bullet)$. (c) Mixed cultures of $S$. cerevisiae SC1 ( $\square$ ) vs $P$. membranifaciens CYC 1086 (O). The killer toxin remaining unbound (bars) was determined and expressed as relative killer activity. Means \pm SD $(n=3)$.

\section{ACKNOWLEDGEMENTS}

This study was supported by grants from the Universidad Complutense-Comunidad de Madrid (910644 and PR1/03-11632), Madrid, Spain. We would like to thank Dr E. Navascues form Agrovin SA for his contribution to this work.

\section{REFERENCES}

Aguilar Uscanga, M. G., Delia, M. L. \& Strehaiano, P. (2000). Nutritional requirements of Brettanomyces bruxellensis: growth and physiology in batch and chemostat cultures. Can J Microbiol 46, 1046-1050. 
Barandica, J. M., Santos, A., Marquina, D., López, F., Acosta, F. J. \& Peinado, J. M. (1999). A mathematical model for toxin accumulation by killer yeasts based on the yeast population growth. J Appl Microbiol 86, 805-811.

Beever, R. E., Larcy, E. P. \& Pak, H. A. (1989). Strains of Botrytis cinerea resistant to dicarboximide and benzimidazole fungicides in New Zealand vineyards. Plant Pathol 38, 427-437.

Bostian, K. A., Elliott, Q. A., Bussey, H., Burn, V., Smith, A. \& Tipper, D. J. (1984). Sequence of the preprotoxin dsRNA gene of type I killer yeast: multiple processing events produce a two-component toxin. Cell 36, 741-751.

Breinig, F., Tipper, D. J. \& Schmitt, M. J. (2002). Krelp, the plasma membrane receptor for the yeast K1 viral toxin. Cell 108, 395-405.

Butler, A. R., White, J. H. \& Stark, M. J. R. (1991). Analysis of the response of Saccharomyces cerevisiae cells to Kluyveromyces lactis toxin. J Gen Microbiol 137, 1749-1757.

Ciani, M. \& Fatichenti, F. (2001). Killer toxin of Kluyveromyces phaffii DBVPG 6076 as a biopreservative agent to control apiculate wine yeasts. Appl Environ Microbiol 67, 3058-3063.

Comitini, F., Ingenis De, J., Pepe, L., Mannazu, I. \& Ciani, M. (2004). Pichia anomala and Kluyveromyces wikerhamii killer toxins as new tool against Dekkera/Brettanomyces spoilage yeasts. FEMS Microbiol Lett 238, 235-240.

Couto, J. A., Neves, F., Campos, F. \& Hoog, T. (2005). Thermal inactivation of the wine spoilage yeasts Dekkera/Brettanomyces. Int $J$ Food Microbiol 104, 337-344.

Druvefors, U. A. \& Schnürer, J. (2005). Mold-inhibitory activity of different yeast species during airtight storage of wheat grain. FEMS Yeast Res 5, 373-378.

Druvefors, U. A., Passoth, V. \& Schnürer, J. (2005). Nutrient effects on biocontrol of Penicillium roqueforti by Pichia anomala J121 during airtight storage of wheat. Appl Environ Microbiol 71, 1865-1869.

Fernandez, M., Ubeda, J. F. \& Briones, A. I. (2000). Typing of nonSaccharomyces yeasts with enzymatic activities of interest in winemaking. Int J Food Microbiol 59, 29-36.

Fleet, G. H. (1990). Yeasts in dairy products. J Appl Bacteriol 68, 199 211.

Fleet, G. H. (1991). Cell walls. In The Yeasts, p. 200. Edited by A. H. Rose \& J. S. Harrison. London: Academic Press.

Fleet, G. H. \& Phaff, H. J. (1973). Effect of glucanases of yeast and bacterial origin on cell walls of Schizosaccharomyces species. In Yeast, Mould and Plant Protoplasts, pp. 33-59. Edited by J. R. Villanueva, J. García-Acha, S. Gascón \& F. Uruburu. London: Academic Press.

Heard, G. M. \& Fleet, G. H. (1987). Occurrence and growth of killer yeasts during wine fermentations. Appl Environ Microbiol 53, 21712174.

Heard, G. M. \& Fleet, G. H. (1988). The effects of temperature and pH on the growth of yeast species during the fermentation of grape juice. $J$ Appl Bacteriol 65, 23-28.

Hutchins, K. \& Bussey, H. (1983). Cell wall receptor for yeast killer toxin: involvement of $(1 \rightarrow 6)-\beta$-D-glucan. J Bacteriol 154, 161-169.

Izgu, F., Altinbay, D. \& Yucelis, A. (1997). Identification and killer activity of a yeast contaminating starter cultures of Saccharomyces cerevisiae strains used in the Turkish baking industry. Food Microbiol 14, 125-131.

Izgü, F., Altinbay, D. \& Türeli, A. E. (2007). In vitro susceptibilities of Candida spp. to Panomycocin, a novel exo- $\beta$-1,3-glucanase isolated from Pichia anomala NCYC 434. Microbiol Immunol 51, 797-803.

Jakobsen, M. \& Narvhus, N. (1995). Yeasts and their possible beneficial and negative effects on the quality of dairy products. Int Dairy J 6, 755-768.
Janisiewicz, W. J. \& Korsten, L. (2002). Biological control of postharvest diseases of fruits. Annu Rev Phytopathol 40, 411-441.

Janisiewicz, W. J., Tworkoski, T. J. \& Kurtzman, C. P. (2001). Biocontrol potential of Metchnikowia pulcherrima strains against blue mold of apple. Phytopathology 91, 1098-1108.

Kimura, T., Kitamoto, N., Imura, Y. \& Kito, Y. (1995). Production of HM-1 killer toxin in Saccharomyces cerevisiae transformed with the PDR4 gene and $\sigma$-sequence-mediated multi-integration system. $J$ Ferment Bioeng 5, 423-428.

Klassen, R. \& Meinhardt, F. (2003). Structural and functional analysis of the killer element pPin1-3 from Pichia inositovora. Mol Genet Genomics 270, 190-199.

Klassen, R., Paluszynski, J. P., Wemhoff, S., Pfeiffer, A., Fricke, J. \& Meinhardt, F. (2008). The primary target of the killer toxin from Pichia acaciae is tRNA(Gln). Mol Microbiol 69, 681-697.

Kurtzman, C. P. \& Fell, J. W. (1998). The Yeasts, a Taxonomic Study. Amsterdam: Elsevier.

Kurtzman, C. P. \& Robnett, C. J. (1998). Identification and phylogeny of ascomycetous yeasts from analysis of nuclear large subunit (26S) ribosomal DNA partial sequences. Antonie Van Leeuwenhoek 73, 331-371.

Laemmli, U. K. (1970). Cleavage of structural proteins during the assembly of the head of bacteriophage T4. Nature 227, 680-685.

Lambrechts, M. G. \& Pretorius, I. S. (2000). Yeast and its importance to wine aroma. South African J Enol Viticult 21, 97-129.

Lenoir, J. (1984). The surface flora and its role in the ripening of cheese. IDF Bull 171, 3-19.

Llorente, P., Marquina, D., Santos, A., Peinado, J. M. \& SpencerMartins, I. (1997). Effect of salt on the killer phenotype of yeasts from olive brines. Appl Environ Microbiol 63, 1165-1167.

Lowes, K. F., Shearmen, C. A., Payne, J., MacKenzie, D., Archer, D. B., Merry, R. J. \& Gasson, M. J. (2000). Prevention of yeast spoilage in feed and food by the yeast mycocin HMK. Appl Environ Microbiol 66, 1066-1076.

Manners, D. J., Masson, A. J. \& Patterson, J. C. (1973). The structure of a $\beta$-(1-3)-D-glucan from yeast cell walls. Biochem J 135, 19-30.

Marín, S., Hodzić, I., Ramos, A. J. \& Sanchos, V. (2008). Predicting the growth/no-growth boundary and ochratoxin A production by Aspergillus carbonarius in pistachio nuts. Food Microbiol 25, 683-689.

Marquina, D., Peres, C., Caldas, F. V., Marques, J. F., Peinado, J. M. \& Spencer-Martins, I. (1992). Characterization of the yeast populations in olive brines. Lett Appl Microbiol 14, 279-283.

Marquina, D., Toufani, S., Llorente, P., Santos, A. \& Peinado, J. M. (1997). Killer activity in yeast isolates from olive brines. Adv Food Sci $19,41-46$.

Martinac, B., Zhu, H., Kubalski, A., Zhou, X. L., Culbertson, M., Bussey, H. \& Kung, C. T. (1990). Yeast K1 killer toxin forms ion channels in sensitive yeast spheroplasts and in artificial liposomes. Proc Natl Acad Sci U S A 87, 6228-6232.

Masih, E. I. \& Paul, B. (2002). Secretion of $\beta$-1,3-glucanases by the yeast Pichia membranifaciens and its possible role in the biocontrol of Botrytis cinerea causing grey mould disease of the grapevine. Curr Microbiol 44, 391-395.

McCracken, D. A., Martin, V. J., Stark, M. J. R. \& Bolen, P. L. (1994). The linear-plasmid-encoded toxin produced by the yeast Pichia acaciae: characterization and comparison with the toxin Kluyveromyces lactis. Microbiology 140, 425-431.

Medawar, W., Strehaiano, P. \& Délia, M. L. (2003). Yeast growth: lag phase modelling in alcoholic media. Food Microbiol 20, 527-532.

Middelbeek, E. J., Hermans, J. M. H. \& Stumm, C. (1979). Production, purification and properties of a Pichia kluyveri killer toxin. Antonie Van Leeuwenhoek 45, 437-450. 
Noronha-da-Costa, P., Rodrigues, C., Spencer-Martins, I. \& Loureiro, V. (1996). Fatty acid patterns of film-forming yeasts and new evidence for the heterogeneity of Pichia membranaefaciens. Lett Appl Microbiol 23, 79-84.

Petering, J. E., Symons, M. R., Langridge, P. \& Henschke, P. A. (1991). Determination of killer yeast activity in fermenting grape juice by using a marked Saccharomyces wine yeast strain. Appl Environ Microbiol 57, 3232-3236.

Petersson, S. \& Schnürer, J. (1995). Biocontrol of mold growth in high-moisture wheat stored under airtight conditions by Pichia anomala, Pichia guilliermondii, and Saccharomyces cerevisiae. Appl Environ Microbiol 61, 1027-1032.

Pfeiffer, P. \& Radler, F. (1984). Comparison of the killer toxin of several yeasts and the purification of a toxin type K2. Arch Microbiol 137, 357-361.

Raposo, R., Gómez, V., Urrutia, T. \& Melgarejo, P. (2000). Fitness of Botrytis cinerea associated with dicarboximide resistance. Phytopathology 90, 1246-1249.

Renouf, V. \& Lonvaud-Funel, A. (2004). Racking are key stages for the microbial stabilization of wines. J Int des Sciences de la Vigne et du Vin 38, 219-224.

Renouf, V., Gindreau, E., Claisse, O. \& Lonvaud-Funel, A. (2005). Microbial changes during malolactic fermentation in red wine elaboration. J Int des Sciences de la Vigne et du Vin 39, 179-190.

Renouf, V., Falcou, M., Miot-Sertier, M., Perello, M. C., de Revel, G. \& Lonvaud-Funel, A. (2006). Interactions between Brettanomyces bruxellensis and other yeast species during the initial stages of winemaking. J Appl Microbiol 100, 1208-1219.

Renouf, V., Strehaiano, P. \& Lonvaud-Funel, A. (2008). Effectiveness of dimethlydicarbonate to prevent Brettanomyces bruxellensis growth in wine. Food Contr 19, 208-216.

Rodrigues, N., Goncalves, G., Pereira-da-Silva, S., Malfeito-Ferreira, M. \& Loureiro, V. (2001). Development and use of a new medium to detect yeasts of the genera Dekkera/Brettanomyces sp. J Appl Microbiol 90, 588-599.

Santos, A. \& Marquina, D. (2004a). Killer toxin of Pichia membranifaciens and its possible use as a biopreservative agent to control grey mould disease of grapevine. Microbiology 150, 2527-2534.

Santos, A. \& Marquina, D. (2004b). Ion channel activity by Pichia membranifaciens killer toxin. Yeast 21, 151-162.

Santos, A., Marquina, D., Leal, J. A. \& Peinado, J. M. (2000). ( $1 \rightarrow 6)-\beta$ D-Glucan as cell wall receptor for Pichia membranifaciens killer toxin. Appl Environ Microbiol 66, 1809-1813.

Santos, A., Sánchez, A. \& Marquina, D. (2004). Yeast as biological agents to control Botrytis cinerea. Microbiol Res 159, 331-338.
Santos, A., Álvarez, M., San Mauro, M., Abrusci, C. \& Marquina, D. (2005). The transcriptional response of Saccharomyces cerevisiae to Pichia membranifaciens killer toxin. J Biol Chem 280, 41881-41892.

Santos, A., San Mauro, M., Abrusci, C. \& Marquina, D. (2007). Cwp2p, the plasma membrane receptor of Pichia membranifaciens killer toxin. Mol Microbiol 64, 831-843.

Schmitt, M. J. \& Breinig, F. (2006). Yeast viral killer toxins: lethality and self-protection. Nat Rev Microbiol 4, 212-221.

Schmitt, M. \& Radler, F. (1987). Mannoprotein of the yeast cell wall as primary receptor for the killer toxin of Saccharomyces cerevisiae strain 28. J Gen Microbiol 133, 3347-3354.

Schmitt, M. J., Klavehn, P., Wang, J., Schönig, I. \& Tipper, D. J. (1996). Cell cycle studies on the mode of action of yeast K28 killer toxin. Microbiology 142, 2655-2662.

Studte, P., Zink, S., Jablonowski, D., Bär, C., von der Haar, T., Tuite, M. F. \& Schaffrath, R. (2008). tRNA and protein methylase complexes mediate zymocin toxicity in yeast. Mol Microbiol 69, 1266-1277.

Suárez, R., Surez-Lepe, J. A., Morata, A. \& Calderon, F. (2007). The production of ethylphenols in wine by yeasts of the genera Brettanomyces and Dekkera: a review. Food Chem 102, 10-21.

Suriyarachchi, V. R. \& Fleet, G. H. (1981). Occurrence and growth of yeasts in yogurts. Appl Environ Microbiol 42, 574-579.

Suzuki, C. \& Nikkuni, S. (1994). The primary and subunit structure of a novel type killer toxin produced by a halotolerant yeast, Pichia farinosa. J Biol Chem 269, 3041-3046.

Takasuka, T., Komiyama, T., Furuichi, Y. \& Watanabe, T. (1995). Cell wall synthesis specific cytocidal effect of Hansenula mrakii toxin-1 on Saccharomyces cerevisiae. Cell Mol Biol Res 41, 575-581.

Takita, M. A. \& Castilho-Valavicius, B. (1993). Absence of cell wall chitin in Saccharomyces cerevisiae leads to resistance to Kluyveromyces lactis killer toxin. Yeast 9, 589-598.

Wang, X., Chi, Z., Yue, L. \& Li, J. (2007). Purification and characterization of killer toxin from a marine yeast Pichia anomala YF07b against the pathogenic yeast in crab. Curr Microbiol 55, 396401.

Wickner, R. B. (1986). Double-stranded RNA replication in yeast: the killer system. Annu Rev Biochem 55, 373-395.

Woods, D. R. \& Bevan, E. A. (1968). Studies on the nature of the killer factor produced by Saccharomyces cerevisiae. J Gen Microbiol 51, 115126.

Young, T. W. (1987). Killer yeasts. In The Yeasts, pp. 131-164. Edited by A. H. Rose \& J. S. Harrison. London: Academic Press.

Edited by: M. Molina 